\title{
La marcha de los Nibelungos y la ética de la responsabilidad de $F$. Hinkelammert
}

F. Hinkelammert nos narró en su reciente curso de doctorado una espléndida ópera de Wagner titulada: La Marcha de los Nibelungos como parábola del capitalismo: Un líder avanza con sus tropas desde el rin a la corte del rey Atila. El viaje está lleno de aınenazas y peligros, pero caminan con ánimo firme y desafiante ante la muerte que los acecha. En el camino encuentran un clarividente que les asegura que nadie va a volver vivo excepto el capellán. Pero no hacen caso y siguen adelante. Cuando están cruzando un río lleno de torbellinos, el líder ordena que arrojen al capellán de la expedición al agua. No tiene ninguna posibilidad de alcanzar la orilla nadando y así, al morir el capellán, se mostrará la falsedad de la profecía. Sin embargo, el capellán es tragado por el ojo del torbellino y lanzado por éste a la ribera. El capellán se salva. Todos están convencidos ahora de que van a morir. Sin embargo deciden, felices, seguir adelante. Parece, pues, que la muerte puede ser fascinante y atractiva. Asegurar que la humanidad se está suicidando y saberlo no significa que va a dejar de quererlo. Frente a esta mística de la muerte, Hinkelammert está intentando elaborar en sus últimos libros: Cultura de la esperanza y sociedad sin exclusión, El mapa del emperador y en un artículo en elaboración aún inédito: "Asesinato es suicidio: de la utilidad de la limitación del cálculo de utilidad", una élica de la responsabilidad que pueda ser la contrarréplica al suicidio colectivo y a La Marcha de los Nibelungos. Es una ética que pretende diferenciarse, en algunas cuestiones cruciales, de otras éticas de la responsabilidad como las de $\mathrm{M}$. Weber, $\mathrm{H}$. Jonas y $\mathrm{O}$.
Apel. El autor que considera más cercano a su propuesta es K. Marx, pero también considera que refluyen en él esquemas de pensar típicamente modernos que acaban atizando La Marcha de los Nibelungos. ¿Cuál es el núcleo de su crítica a la modernidad que le conduce a formular serias reservas a las éticas de la responsabilidad formuladas por los anteriores autores? ¿Cuál es la originalidad y qué dificultades acarrea a nuestro juicio el proyecto de Hinkelammert? ¿Una ética filosófica sólo puede contraponer a la Marcha de los Nibelungos una ética de la responsabilidad sin fundamentación, tal como la concibe F. Hinkelammert? Son las cuestiones que intentaremos dilucidar en este comentario. Para ello empezaremos por su crítica a la ética de la responsabilidad de Max Weber.

\section{Weber o el principio de Caifás}

En la conferencia que con el título de "La ciencia como vocación" pronunció Max Weber en la Asociación Libre de Estudiantes de Munich, en el invierno de 1919, Weber dice que al científico se le debe exigir: "Que tenga la probidad intelectual necesaria para comprender que existen dos tipos de problemas perfectamente heterogéneos: por una parte, la constatación de los hechos, la determinación de contenidos lógicos o matemáticos o de la estructura interna de fenómenos culturales; por la otra, la respuesta a la pregunta por el valor de la cultura de sus contenidos concretos y, dentro de ella, de cuál debe ser el comportamiento del hombre en la comunidad cultural y en las asociaciones políticas"'. Para Weber, pues, todo científico debe diferenciar con

1. Weber, M., El politico y el cientifico, Madrid: Alianza, 1969, pp. 215-216. 
rigor lo que son hechos de lo que son valores. El profesor que enseña una disciplina científica debe transmitir a sus discípulos "hechos" pero no "valores", pues en ese mismo momento deja de ser un científico. No cabe hacer una defensa "científica" de los valores, ya que "los distintos sistemas de valores existentes libran entre sí una batalla sin solución posible"2. Para Weber, los únicos juicios propiamente científicos son los "juicios con arreglo a fines". La elección de estos fines, en cambio, escapa a la racionalidad de las ciencias. Los "juicios con arreglo a valores", a los cuales la ciencia no tiene acceso, del tipo prefiero comer papas que comer frijoles o prefiero vivir a morir, o viajar a trabajar, Weber los llama juicios de "racionalidad material". El valor es lo que me hace decidir y pronunciarme sobre uno u otro. La ciencia no tiene aquí nada que decir. Pero una vez determinados los fines, la ciencia lo que sí puede hacer es hablar acerca de la racionalidad de los medios. Si quiero comer frijoles es más eficaz hacer esto que lo otro, etc. Es lo que Ilamará la "racionalidad formal" de las ciencias. En la elección de fines hay una intrínseca conflictividad que es imposible de dirimir de modo racional. Cuando se trata de valores, siempre hay un relativismo inextricable e insoluble. Pero la conclusión de Weber no es que no sea posible ninguna ética, sino que una ética que pretenda ser universal debe cambiar su método. Para Weber, la función del método en ética ya no es dirimir las contiendas entre valores sino evidenciarlas, haciendo ver qué postura práctica deriva lógicamente de cada visión del mundo, y cuáles son las consecuencias últimas y significativas de cada opción axiológica, de modo que - mediante él- el individuo se dé cuenta del sentido último de sus propias acciones? Lo que el método aporta no es otra cosa, pues, que sentido de la responsabilidad. Y esto se logra tanto mejor cuanto más se controle, por parte del maestro o el profesor, el deseo de imponer su propia postura personal, el propio sistema de valores ${ }^{4}$.

A esta manera de proceder, Weber la denomina ética de la responsabilidad. La ética de la responsabilidad se pregunta por las consecuencias de sus acciones. Su acción es una acción racional calculada con arreglo a fines. La ética de la convicción, en cambio, no tiene en cuenta las consecuencias, su racionalidad no se reduce a la razón estratégica o instrumental, porque en ella la razón apunta o alcanza a algo que está más allá de todo cálculo y cree que los fines nunca justifican los medios. Su acción es una acción racional con arreglo a valores sin relación alguna con los resultados. Mientras $M$. Weber relega esta ética de la convicción al ámbito del individuo y de lo subjetivo, considera la ética de la responsabilidad como la propia de la sociedad y del político: "Quien hace política pacta con los poderes diabólicos que acechan en tomo de todo poder. Los grandes virtuosos del amor al prójimo y del bien cósmico, de Nazaret, de Asís o de los palacios reales de la India, no operaron con medios políticos o con el poder. Su reino no era de este mundo, pese a que hayan tenido y tengan eficacia en él. Quien busca la salvación de su alma y la de los demás, que no la busque por el camino de la política, cuyas tareas, que son muy otras, sólo pueden ser cumplidas mediante la fuerza. El genio o demonio de la política se encuentra en tensión interna con el dios del amor, incluido el dios cristiano en su configuración eclesiástica, y esta tensión puede convertirse en todo momento en un conflicto sin solución"s.

La ética de convicción contradice la responsabilidad polílica. La razón de Estado es la utilización de medios malos para conseguir fines buenos: "Los medios quedan en la práctica siempre justificados por el fin, y ésa es la razón de ser del poder coercitivo y la violencia institucionalizada del Estado. El Estado siempre tiende a hacer bueno el llamado «principio de Caifás": Conviene que muera un hombre solo (e inocente) por todo un pueblo"6. Ahora bien, esta división entre actuaciones con arreglo a fines y actuaciones con arreglo a valores no sólo sirve para trazar una línea divisoria entre la razón de Estado o política y la razón individual, sino entre épocas y sociedades. Así, mientras la sociedad medieval actúa con arreglo a valores, la sociedad contemporánea actúa con arreglo a fines, y si bien subsisten culturas y sociedades que todavía establecen sus relaciones sobre la base del respeto de valores (cultu-

2. Ibid., p. 216.

3. Ibid., pp. 223-224.

4. Ibid., p. 223.

5. Weber, M., op. cit., pp. 173-174.

6. Gracía, Diego. Fundamentos de bioética, Madrid: Ed. Eudema Universidad, 1989, p. 502 y ss. 
ras deontológicas), es importante señalar que —para Max Weber - toda cultura acabará siendo de tipo teleológico en la medida en que la acción económica adquiera prioridad. La acción económica o de mercado es el prototipo de la ética de la responsabilidad: "Los partícipes en el mercado orientan su acción que es «medio» por determinados intereses económicos propios, típicos y subjetivos que representan el «fin» y por determinadas expectativas típicas, que la previsible conducta de los demás permite abrigar, las cuales aparecen como condiciones de la realización del «fin» perseguido"7. Es más, afirma que, en el rigor de los términos, sólo con la acción económica capitalista la política se ha hecho estrictamente racional. Su tesis es que el capitalismo surgió al imponerse la racionalidad en todos los órdenes de la vida: la contabilidad racional, la técnica racional, el derecho racional, etc. El mundo moderno supone la racionalización de la vida y del Estado. Por eso Weber denomina al Estado moderno Estado racional. El Estado racional es aquél que no se halla ya en manos de políticos clásicos, sino de funcionarios a los que les interesan más las formas que los contenidos". Los políticos no son en él más que los grandes estrategas de la administración pública. Los líderes de la razón instrumental.

Hinkelammer", siguiendo - a mi modo de vermuy de cerca a la escuela de Francfort, insistirá que en la cultura occidental, hoy universalizada de facto, cada vez se ha ido imponiendo con mayor fuerza la razón teleológica o racionalidad calculadora: "En la medida en que este concepto de razón, cuyo predominio no es separable, en absoluto, de la sociedad burguesa, tiene ante la vista exclusivamente lo razonable para el que piensa, para el sujeto, se le puede llamar concepto de la razón subjetiva. Esta tiene que ver, ante todo, con la relación entre finalidades y medios con la adecuación de los modos de comportamiento a los fines, que, como tales, se aceptan más o menos, sin someterlos por su parte,

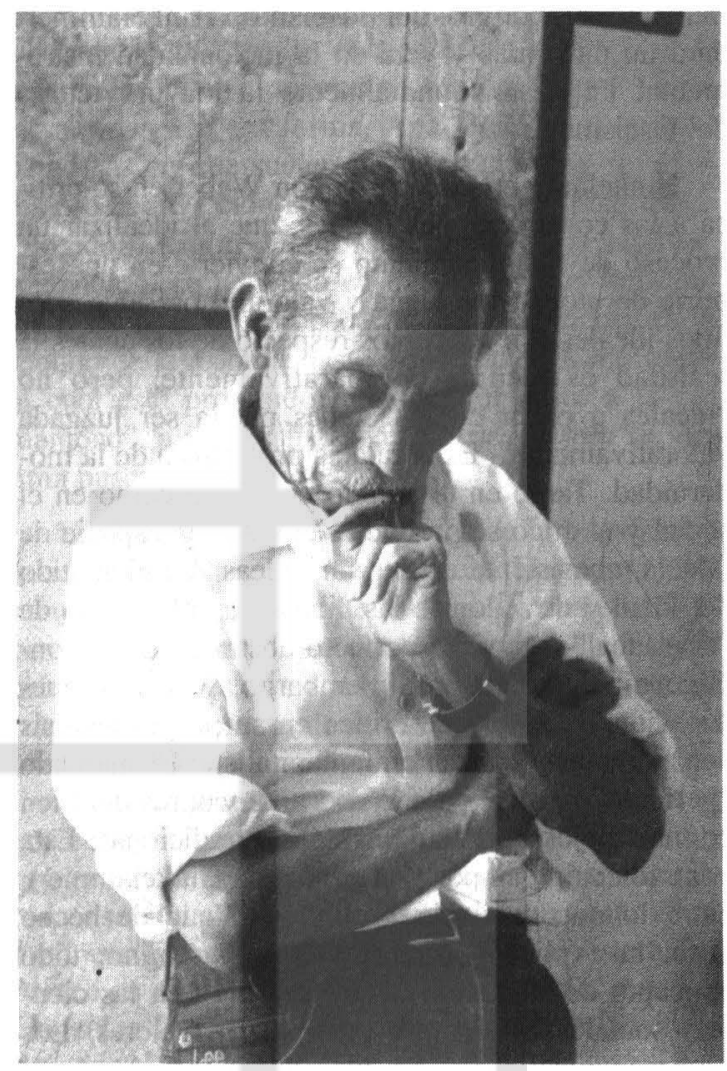

en general, a una justificación razonable"'10. La racionalidad instrumental entiende por razonable únicamente el que algo sea conveniente para los intereses del sujeto. Tras el desencantamiento del mundo, el hombre ya no puede creer más que en esta razón instrumental. Y en ello verá precisamente la Escuela de Francfort el fracaso de la Ilustración. Una vez instaurada la razón instrumental, afirma Horkheimer, es imposible decir que un sistema político sea irracional, por cruel o despótico que sea, con tal que funcione ${ }^{\prime \prime}$. Por eso, O. Apel y en general los pensadores de la escuela de Francfort verán en el prag-

7. Weber, M., Economía y sociedad, México: FCE, 2 da ed., 1979, p. 24.

8. Weber, M., ibid., pp. 173-180 y 716-752.

9. Seguimos aquí su libro Cultura de la esperanza y sociedad sin exclusión, Editorial DEI, Costa Rica, 1995, fundamentalmente el capítulo III: "La irracionalidad de lo racionalizado. Comentarios metodológicos sobre la racionalidad instrumental y su totalización", y su último libro El mapa del emperador, Editorial DEI, Costa Rica, 1996, principalmente el capítulo I: "La postmodernidad: eterno retorno de lo nuevo", donde se reintroduce el capítulo del anterior libro complementado con un análisis de la causalidad indirecta y la imposibilidad de una previsión de la acción humana.

10. Horkheimer, M., "Sobre el concepto de la razón", en Adorno, Theodor y Horkheimer, M., Sociológica, Madrid: Taurus, 1966, p. 258.

11. Ibid., p. 270. 
matismo el peligro del fascismo. Hinkelammert dará un paso más y verá en la racionalidad instrumental impuesta mundialmente la mayor victoria del fascismo.

Hinkelammert concuerda con Weber en su crítica a las construcciones ideales, que al idealizar un proceso de funcionamiento se convierte en una especie de utopía que juzga y valora el presente. Los tipos ideales son conceptos respecto de los cuales la realidad es medida comparativamente, pero no "ideales a partir de los cuales pueda ser juzgada valorativamente". Es la falacia prototípica de la modernidad. Tanto en el ámbito científico como en el social y el ético se produce siempre una especie de falacia, consistente en derivar "ideas" en el sentido del ideal y de valor de las "ideas" en el sentido de "tipo ideal" o modelo perfecto abstraído de la contingencia de las cosas. Sin embargo, Weber no puede evitar hacer lo que critica en su propio análisis del mercado y la economía capitalista. El mercado "perfecto" realiza, para Weber, los valores del bien común mejor que cualquier ética tradicional. Esta contradicción que pone en evidencia Hinkelammert, entre lo que denuncia Weber y lo que de hecho hace, la explica porque, en último término, todo concepto de situación ideal construido en las ciencias sociales es siempre portador de valores. Los procesos idealizados de funcionamiento implican valores. Es imposible construir tipos ideales que no sean idcales en el sentido de valores, y en Weber encuentra la comprobación más clara de esta tesis ${ }^{12}$.

Lo que nos está denunciando Hinkelammert es que Weber, bajo el nombre de ética de la responsabilidad, nos vende una ética de convicción, una ética de valores y de principios de la peor calaña porque encima no se reconoce como tal. Se trata de la élica de principios capitalista que bajo la crítica al rigorismo de las éticas de la convicción, nos introduce su propio rigorismo. Lo más grave es que esta ética de la responsabilidad o razón instrumental nos lleva a la paradoja de poner en peligro la sobrevivencia de humanidad en su conjunto, la naturaleza misma y la convivencia mínima entre los hombres. Cuanto más fiel soy a esta racionalidad medio-lin, más me precipito hacia el abismo. Hinkelammert lo expresa gráficamente con la afirmación de que, cuanto más aplicamos esta racionalidad calculadora más rápidamente cortamos la rama sobre la que estamos sentados. La acción orientada por la eficiencia de la relación medio-fin y la competencia como medio por el cual esta eficiencia es maximizada, aparecen en $\mathbf{M}$. Weber como categorías últimas del pensamiento. En consecuencia, en nombre de la ciencia se excluye el análisis de la relación entre los fines realizados y la vida del actor. Hinkelammert no cuestiona el hecho de que una ciencia empírica deba basarse en juicios de hecho y no en juicios de valor. Sin embargo, considera que hay juicios de hecho, objeto de las ciencias empíricas, que no son juicios medio-fin. Estos juicios de hecho son juicios sobre el efecto de un fin realizado en la propia vida del actor, que es la condición de posibilidad de todo fin. El cálculo medio-fin como tal no revela esta racionalidad fundamental que Hinkelammert llamará, al igual que Marx, racionalidad reproductiva. Lo que a la luz de la racionalidad medio-fin parece racional, a la luz de la racionalidad reproductiva del sujeto puede ser perfectamente irracional. Cuando Weber habla de ética de la responsabilidad, postula la responsabilidad del científico y del hombre del mercado de no dejarse llevar por consideraciones sobre la vida y la muerte de los actores. Por eso, lo que Weber llama ética de la responsabilidad es de hecho para Hinkelammert una ética de la irresponsabilidad más absoluta. Una ética que en nombre de la negación de todo principio se arrodilla ante el principio de Caifás.

\section{Apel o la aproximación asintótica a un ideal}

Apel ve también en la razón instrumental siempre larvado el fascismo y el peligro de autodestrucción. Pero aunque coinciden en el diagnóstico con F. Hinkelammert, el remedio es muy diferente. Apel considerará que tan peligroso es absolutizar el momento deontológico de la élica como el momento teleológico. Entre las éticas de la convicción o de valores y las éticas de responsabilidad no hay oposición, sino complementariedad. Ambas, absolutizadas, nos arrojan al rigorismo moral. Para superar a la razón instrumental, Apel acude a la razón práctica kantiana. Lo que Apel critica a Kant es el haber condescendido excesivamente con los viejos planteamientos metafísicos ${ }^{13}$. El imperativo categórico kantiano caería de algún modo en las redes de la falacia naturalista; precisamente porque se funda en

12. Hinkelammert. F., Culiura de la esperanza y sociedad sin exclusión, op, cit., p. 233 y ss.

13. Apel, K. O.. La transformación de la filosofia. Vol. 2, Madrid: Taurus, 1985, p. 345. 
un "hecho de razón" que actúa como supuesto material necesario. Apel piensa que para evitar esta dificultad es necesario interpretar el "factum rationis" kantiano como algo implicado en la capacidad de argumentar. En la comunicación humana hay, desde luego, muchos contenidos subjetivos, pero hay al menos algunas reglas que no pueden ser consideradas ni como meras convenciones ni como imperativos hipotéticos, es decir, como reglas al servicio de un fin material concreto, como los que se propone la razón estratégica. Estas reglas de la comunicación, que no son subjetivas ni hipotéticas, son formales, transcendentales y a priori y constituyen la condición de posibilidad de toda comunicación intersubjetiva. Según Apel, estas reglas se nos manifiestan con fuerza obligante $y$ vinculante ${ }^{14}, y$ se apartan de la racionalidad meramente estratégica. Entonces, a partir de una filosofía primera que consistiría precisamente en un análisis del lenguaje, es posible reelaborar la idea —en Kant propuesta aún metafísicamente- de una razón autónoma, moralmente legisladora, que $a$ priori está referida a una comunidad de seres racionales con igualdad de derechos en tanlo que seres de fines en sí mismos ${ }^{15}$.

Apel formula así el principio de universalización implícito en todo aclo lingüístico: Toda norma válida debe satisfacer la condición de que las consecuencias y los efectos colaterales que previsiblemente resultan de su observación general para la satisfacción de los intereses de cada individuo, deban poder ser aceptados sin constreñimiento por todos los afectados. Apel asume, de ese modo, la ética de la responsabilidad de Max Weber. Cualquier norma para que sea legítima debe tomar en cuenta la consideración de las consecuencias y los efectos colaterales ya en el mismo proceso de formación de las normas. De esa forma, Apel pretende evitar las paradojas en que suelen incurrir las éticas de valores o de convicción al exacerbar el momento deontológico. Siempre tendré que actuar de manera estratégica, pero teniendo en cuenta a todos los afectados y no deberé proceder, de ningún modo, en el sentido de la recomendación rigorista de Kant, según la cual está prohibido mentir, "por amor a la humanidad", a un asesino potencial respecto a su víctima buscada ${ }^{16}$.

Hinkelammert ve en esta ética de la responsabilidad de Apel un enorme potencial liberador: "Supongamos que el cobro de la deuda externa del Tercer Mundo lleva por sus consecuencias a la destrucción de los seres humanos y de la naturaleza; entonces, el representante de la ética de responsabilidad tendría que levantarse en su contra. Pero, entonces, las protestas en contra del cobro de esta deuda $y$, por ende, en contra del FMI, de nuestros bancos y gobiernos, serían acciones gujadas por una ética de responsabilidad"1?. Sin embargo, si bien esta ética, en líneas generales, propicia reformas al sistema no parece en ningún caso ponerlo en cuestión. Antonio González ${ }^{18}$ ha mostrado con agudeza que las éticas del discurso son proclives a la legitimación de una forma de vida concreta, no por un mero desliz accidental de alguno de sus promotores, o por unos simples condicionamientos sociológicos de la teoría ${ }^{19}$, corregibles desde la misma apelación a la comunidad ideal de diálogo, sino por el mismo punto

14. Apel, K. O., Estudios éticos, Barcelona: Alfa, 1986, p. 74.

15. Ibíd., pp. 85-86.

16. Véase para el tratamiento del tema F. Hinkelammert, Cultura de la esperanza y sociedad sin exclusión, op. cit., p. 246 y ss.

17. Ibíd., p. 249.

18. González, A., Filosofía primera, Madrid: Ed. Trotta, 1997.

19. La anécdota que refiere Antonio González es que mientras Apel y Ellacuría reconocen el mismo hecho, la imposibilidad de universalizar la forma de vida occidental, las consecuencias que sacan son distintas. Para el primero se trata de que los países pobres aprendan a distinguir entre una auténtica calidad de vida y el nivel de vida de los países ricos; para el segundo, de que si los países ricos no pueden universalizar sus formas de vida, entonces éstas son éticamente reprobables. González, A., "Fundamentos filosóficos de una civilización de la pobreza", ECA, 583. San Salvador: UCA, mayo, 1997, p. 419. Es importante resaltar que Apel sigue manteniendo ante las críticas latinoamericanas la teoría desarrollista. Lo único que concede es que hay problemas en las etapas del desarrollo debido al bloqueo de los países más ricos a la evolución progresiva de los más pobres, y que sería muy bueno "que los habitantes de los llamados países subdesarrollados no imitaran la forma específica de progreso en el desarrollo que han seguido los pueblos ricos del norte durante el último siglo". Véase Apel, K., "La pragmática trascendental", en Dussel, E., Debate en torno a la ética del discurso de Apel, Siglo XXI editores, pp. 50 y ss. 
de partida de la ética del discurso. Se sienta como un hecho el valor primero del discurso (diálogo, consenso, etc.) que coadyuvan las instituciones y las formas de vida occidental. De ese modo, lo último que se cuestiona es este estilo de vida y las instituciones que lo hacen posible. Al presuponer el valor supremo del diálogo se acreditan las instituciones y las formas de vida que la posibilitan pero que no son de hecho universalizables. Como denotan muchos de los textos de Apel, siempre se da por supuesto que los países occidentales están más cerca de la comunidad ideal de comunicación que los países pobres, su manera de vivir parece gozar de una mayor legitimidad ética que la de otras culturas. Aunque la ética del discurso pudiera caer en la cuenta en un diálogo auténtico no sólo de la imposibilidad de universalizar la forma de vida occidental, sino también de la necesidad de someter a revisión crítica esa forma de vida, seguiría siendo cierto que la ética del discurso está atravesada, de hecho, por la tendencia a pensar antes en la moderación de las expectativas de desarrollo de los pobres que en la reforma del estilo de vida Occidental, y que su propio método tiende a inhibirla de desenmascarar sus presupuestos fácticos.

Hinkelammert también repara en esta tendencia de la ética del discurso a legitimar las actuaciones de los países ricos, y resalta la incongruencia de que Apel afirme que no se puede renunciar a las mentiras, al engaño e incluso a la violencia en el caso de una confrontación con un criminal o con una organización como la Gestapo y, sin embargo, no ponga el mismo énfasis en hacer ver que los estados democráticos actúan allende sus fronteras "como la Gestapo": Así se pregunta (entre cientos de ejemplos que podrían ponerse) si fue justificado el atentado contra Augusto Pinochet, que realizó la resistencia chilena en el período del terrorismo del Estado en Chile. "El problema sigue siendo actual, porque quienes realizaron el atentado fueron condenados a cadena perpetua y el Estado de derecho chileno confirmó la condena, mientras los terroristas del Estado andan libres y tienen asientos de honor. Los terrorismos de Estado en América Latina siempre fueron apoyados por los Estados de derecho de Europa y Estados Unidos"20. Del mismo modo, destaca la paradoja de que Apel se acerque tanto al problema real de las utopías modernas y, sin embargo, no repare que vivimos en plena utopía conservadora. Apel no ve con suficiente claridad que este pensamiento del status quo de los llamados pragmáticos o realistas que absolutizan el sistema de la sociedad moderna es precisamente el pensamiento utópico del siglo XX. En nombre de esas utopías conservadoras es destruido nuestro mun$\mathrm{do}^{21}$.

Hinkelammert considera que hay elementos consustanciales a la ética del discurso, más allá de lo que podría pensarse que son simplemente motivos, opciones políticas y condicionamientos personales de Apel, que le impiden ejercer una crítica radical del sistema. El elemento que más lastra la ética de la responsabilidad de Apel es para F. Hinkelammert la aproximación asintótica a un ideal. E1 concepto de la comunidad ideal de comunicación es derivado mediante un proceso de abstracción a partir del concepto de la comunidad real de comunicación. La comunidad ideal es, por decirlo así, un espejo de lo que subyace desde siempre a la comunidad real de comunicación. El lugar de los "principios constitutivos" de la experiencia kantiana es ocupado en Apel por los "principios regulativos", pero presuponiendo que los principios regulativos in the long run tienen que revelarse como constitutivos, a pesar de que tengamos que aplazar la meta de un consenso ideal a un futuro infinito y que no confiemos su realización a una filosofía autosuficiente, sino a una mediación entre experiencia hermenéutica y acción, guiada filosóficamente. De esta manera, Hinkelammert considera que Apel transforma la meta fantasmagórica de una aproximación asintótica infinita en el principio constitutivo de la ética del discurso ${ }^{22}$.

De hecho, el esquema es casi un prototipo del pensar moderno. Así, en economía, la competencia real o competencia "imperfecta", por medio de un proceso de abstracción, en el cual el mercado es visto como un proceso de funcionamiento, será medida por su grado de aproximación a la "competencia perfecta". Al igual que en la argumentación apeliana, la competencia perfecta es explicitada como una situación ideal de competencia implicada desde siempre en el proceso real de com-

20. Hinkelammert, F., Cultura de la esperanza. op. cit., p. 266.

21. Ibid., p. 209 y ss.

22. Ibid., p. 254 y ss. 
petencia. En las ciencias sociales, el marxismo contrapondrá a la división del trabajo real, en el sentido de una comunidad de comunicación de bienes, una situación ideal de la división social del trabajo que desde siempre se halla implicada en la situación real de la división del trabajo. Este esquema moderno de pensamiento tiende a hacer desaparecer la realidad en nombre de su propia idealidad. La imaginación de la aproximación asintótica infinita de la realidad a su situación ideal es como un velo que hace invisible la condición humana En el lugar de la realidad se pone un proceso de aproximación asintótica a la situación ideal, que pierde de vista la contingencia y finitud del hombre y de las cosas y es además contradictorio: "La aproximación asintótica infinita a los conceptos o situaciones ideales que se abstraen de la contingencia del mundo tiene que interpretar pasos finitos hacia una meta infinitamente lejana como aproximaciones. Expresado en términos matemáticos: liene que sostener que la cifra 100 se encuentra más cerca de lo infinito que la cifra 1 . En la forma del progreso técnico, tiene que sostener que el reloj atómico, que pierde un segundo en trescientos millones de años, se encuentra más cerca del reloj exacto que el reloj de cocina de nuestra abuela, que pierde todos los días algunos minutos. No obstante, medido por el reloj exacto, ningún relnj se encuentra más cerca a éste que cualquier otro. El reloj atómico se encuentra tan infinitamente lejos del reloj exacto, como el reloj de la cocina de nuestra abuela. Es más exacto apenas en términos relativos, es decir, medido en relación con el reloj de nuestra abuela. ¿Se encuentra el ser humano de hoy, que tiene una esperanza de vida doble en relación con los seres humanos de hace quinientos años, más cerca de la vida eterna que ellos?"2?.

En este punto, Hinkelammert comparte la visión de Max Weber en el sentido de que todas estas situaciones ideales son utopías. Ello le llevará a repudiar la noción moderna de "progreso"24 y de desarrollo moral. "Cada época está igualmente cerca de Dios; o igualmente lejos" "s. Si excluimos cualquier aproximación asintótica infinita a situaciones ideales, cae entonces la tesis central de
Apel de identidad, in the long run, entre los principios constitutivos y regulativos de experiencia. Apel puede sostener esta identidad únicamente porque presupone un progreso infinito de aproximación asintótica a la situación de una comunidad ideal de comunicación.

\section{H. Jonas o el sometimiento a la autoridad de la naturaleza}

Si hasta hace poco las dos corrientes preponderantes de la ética (las éticas teleológicas y las deontológicas) han incidido en considerar al hombre, respectivamente, bien como un hacedor, teledirigido hacia unos fines, que busca la utilidad o bien como un ciudadano que se atiene deontológicamente a leyes morales y deberes, Hans Jonas considerará que hoy en día una ética de la responsabilidad debe convertirse en el centro de atención superando la tensión entre ambas. El desarrollo tecnológico y el inmenso poder acumulado por la humanidad hace que ninguna de las éticas habidas hasta ahora nos instruya acerca de las reglas de bondad y maldad a las que las modalidades enteramente nuevas del poder y de sus posibles creaciones han de someterse. "La tierra virgen de la praxis colectiva en que la alta tecnología nos ha introducido es todavía, para la teoría ética, tierra de nadie" "It. Hasta hace unas pocas décadas la presencia del hombre en el mundo era un dato primero e incuestionable del cual partía cualquier idea de obligación en el comportamiento humano. Ahora esa presencia misma se ha convertido en objeto de obligación. "Así, pues, si la nueva naturaleza de nuestra acción exige una nueva ética de más amplia responsabilidad, proporcionada al alcance de nuestro poder, entonces exige también - precisamente en nombre de esa responsabilidad- una nueva clase de humildad. Pero una humildad no debida, como antes, a nuestra insignificancia, sino a la excesiva magnitud de nuestro poder, es decir, al exceso de nuestra capacidad de hacer sobre nuestra capacidad de prever y sobre nuestra capacidad de valorar y juzgar. Ante el potencial casi escatológico de nuestros procesos técnicos, la ignorancia de las consecuencias úllimas será en sí

23. Ibid., p. 240.

24. Una alternativa interesante para pensar el dinamismo de la historia es la de la apropiación de posibilidades que desarrolla X. Zubiri. Véase, Zubiri, X., Estructura dinámica de la realidad, Madrid: Alianza Editorial, 1989.

25. Es la linda cita de Ranke que utiliza Hinkelammert para clausurar el tema.

26. Jonas, H., El principio de responsabilidad, Barcelona: Herder, 1995, p. 15. 
misma razón suficiente para una moderación responsable"27.

Ser responsable significa percatarse de que nos hallamos ya en una realidad compleja y de que nuestro poder se ha hecho incalculable, por lo que no bastan para guiar la acción ni la mera eficacia ni el puro deber. "Hasta ahora la reflexión ética se ha concentrado en la cualidad moral del acto momentáneo mismo. Ninguna ética anterior tuvo que tener en cuenta las condiciones globales de la vida humana ni la existencia misma de la especie. Bajo el signo de la tecnología, la ecología, el mercado mundial y en definitiva los procesos de mundialización, la ética tiene que ver con acciones de un alcance causal que carece de precedentes y que afecta al futuro, a ello se añaden unas capacidades de predicción, necesariamente incompletas pero que superan todo lo anterior" $2 k$. La existencia del planeta, la duración de la vida, el aumento de la duración de la vida humana, la configuración genética del ser humano, cada vez penden más de una decisión humana. Por tanto, una ética que pueda servirnos de orientación, ante las capacidades extremas que hoy poseemos, debe partir del principio de responsabilidad, es decir, de tener en cuenta los efectos de nuestras acciones sobre los demás y sobre la naturaleza para preservar la existencia de la vida humana. Ya no podemos confiar más en ninguna razón inmanente en la historia y si lo hiciéramos sería una imprudencia absoluta.

Hinkelammert apreciará elementos muy conservadores en la crítica que realiza $H$. Jonas al Principio esperanza de Bloch, no por lo que critica sino en lo que deja de criticar, sobre todo en la medida en que desenmascara el mecanismo de la utopía de los idealistas dejando intacto el modo de operar de este mismo mecanismo en autores como Weber, que se hacen pasar por "realistas"2y. Pero hoy es más importante que nunca, a mi modo de ver, mantener un cierto agnosticismo respecto a lo que podría ser la esencia del hombre. En eso $\mathrm{H}$. Jonas no se equivoca: "El hombre auténtico estuvo ahí presente desde siempre, con su nobleza y su bajeza, con su grandeza y su miseria, con su felicidad y su tormento, sus justificaciones y sus culpas, en definitiva con la ambigüedad que le es indisociable... El hombre utópico hoy sólo puede ser un homúnculo de la futurología sociotecnológica, condicionado de manera infame para el buen comportamiento y el bienestar. Esta es una de las cosas que hemos de temer del futuro. Lo que habrá de esperarse -al contrario que en el escatológico Principio esperanza- será que también en el futuro todo contento produzca su descontento, toda posesión su deseo, toda paz su desasosiego, toda libertad su tentación y toda felicidad su infelicidad... El error de la utopía es, pues, un error de la antropología supuesta por ella, un error de su concepción de la esencia del hombre. El presente del hombre - distinto del de la larva, cuyo destino es convertirse en mariposa- es siempre plenamente válido en ese problematismo que él es" ${ }^{\text {"30. }}$. El libro de H. Jonas, publicado en 1979, se titulo El principio de responsabilidad precisamente como réplica Al principio esperanza de E. Bloch. Lo más interesante de la crítica a Bloch es que Jonas nos hace ver que el miedo pertenece a la responsabilidad tanto como la esperanza. "En ese vacío (que es al mismo tiempo el vacío del actual relativismo de los valores) es donde se sitúa esta investigación. ¿Qué podrá servirnos de guía? ¿El propio peligro que prevemos! Es en destellos procedentes del futuro, es en la mostración anticipada su escala planetaria y de su calado humano, donde primeramente podrán descubrirse los principios éticos de los que se derivarán nuevos deberes del nuevo poder. A esto lo llamo yo "heurística del temor" sólo la previsible desfiguración del hombre nos ayuda a alcanzar aquel concepto de hombre que ha de ser preservado de tales peligros" "3!. Pero, desgraciadamente, este planteamiento antropocéntrico inicial de $\mathrm{H}$. Jonas es abandonado, los fines no sólo pertenecen al ser humano sino a la naturaleza entera, a la autoridad de la cual debe subordinarse de nuevo el hombre ${ }^{32}$.

27. Ibíd., p. 56. Como él mismo señala, se trata del intento de elaboración no utópica de la ética de la responsabilidad.

28. Ibid., p. 16.

29. Hinkelammert, F., Cultura de la esperanza y sociedad sin exclusión, op. cit., p. 245.

30. Jonas, H., op. cit., p. 348 y ss.

31. Ibid, p. 66.

32. "Al ser la subjetividad, en cierto sentido, un fenómeno superficial de la naturaleza -la punta visible del iceberg- ella habla por el interior mudo. Dicho de otra forma: el fruto delata algo de la raíz y del tronco de los que ha crecido. La materia ha de albergar ya en sí, en forma no subjetiva, fines". Jonas, H., op. cit., p. 131. 
Hinkelammert se distanciará de uno de los aspectos más inquietantes de la ética de la responsabilidad de $\mathrm{H}$. Jonas que es su proyección política antidemocrática y conservadora. H. Jonas considera que las instituciones democráticas, aún en el supuesto de una democracia mundial ideal donde cada ciudadano contara con un voto, no pueden responder adecuadamente con sus principios y procedimientos habituales a las nuevas exigencias. Esto es así debido a que en los procedimientos democráticos sólo se obliga a tomar en consideración intereses presentes. Más el futuro no está representado en ningún grupo y, por tanto, no constituye una fuerza capaz de hacer notar su peso en la toma de decisiones. Los no nacidos carecen de poder. La consideración que se debe a los no nacidos no tiene tras de sí ninguna realidad política en el proceso de decisión actual; y cuando los no nacidos tengan la posibilidad de exigirla, nosotros ya no existiremos. H. Jonas cree que hay valores que están por encima del consenso. El sabio conoce estos valores y, por tanto, debe gobernar por encima de las mayorías. Volvemos pues a una situación platónica y al replanteamiento virulento de una vicja paradoja política: el consenso ideal, aún el consenso preconizado por Apel en la comunidad ideal de comunicación no evita la posibilidad de suicidio, si éste es asumido por todos los afectados quedando excluidos todos los no-nacidos, y si se quieren evitar los efectos perversos del consenso parece que las instituciones democráticas deberían estar mediatizadas por instituciones no democráticas que usualmente producen efectos más perversos que las democráticas. Dicho de otro modo, en el plano ético, el consenso, aun el consenso de una mayoría mundial, parece que puede producir siempre leyes y situaciones injustas. Pero si el consenso no es la última palabra sobre la verdad y la justicia, entonces, ¿en nombre de qué órgano o instancia puedo apelar a esta verdad y justicia? ¿No es siempre más justo un valor producto del consenso que un valor producto del disenso de una minoría? ¿No cabe siempre la sospecha de que las minorías intenten hacer pasar por "universal" y exigible a cualquiera lo que no son más que sus vanos sueños y deseos? Si el consenso y la democracia más plena no son la última palabra sobre la verdad y la justicia, ¿no hay ninguna otra posibilidad para fundamentar la justicia y el bien que la apelación a un orden natural o a la razón de la fuerza y del poder? Es el problema de la fundamentación ética ${ }^{33}$. $\mathrm{Y}$ aquí $\mathrm{H}$. Jonas, contra lo que parecía su propósito, no hace más que reactualizar la ética teleológica de Aristóteles y sus implicaciones políticas. Sólo el sabio conoce el orden justo.

Mientras la ética de la responsabilidad en Hinkelammert no se fundamenta o, en todo caso, como veremos más adelante, se deriva de una voluntad de vida y de una ciencia social crítica que nos hace ver que hoy la cuestión es decidir sobre la vida o la muerte de la humanidad misma, en Jonas la ética de la responsabilidad tiene un fundamento metafísico. No deja de ser curioso que después de criticar tanto a las éticas teleológicas y deontológicas las acabe recuperando plenamente, de una manera mucho más plena que el propio Apel. El principio de responsabilidad de $\mathrm{H}$. Jonas, por el cual el imperativo de que haya una humanidad y de perseverar en el ser es nuestro primer deber, se fundamenta en una ontología o metafísica. La justificación de una ética tal que ya no permanezca circunscrita al ámbito inmediato e interpersonal de nuestros contemporáneos habrá de prolongarse hasta la metafísica, pues sólo desde la metafísica cabe hacer la pregunta de por qué debe haber, en general, hombres en el mundo y de por qué es, por tanto, válido el imperativo incondicional de garantizar su existencia futura. Frente a la renuncia a la metafísica de la filosofía contemporánea, aquí se intentará llevar a cabo una fundamentación naturalista de la ética, al reactualizar la cuestión premoderna de la relación entre el ser y el deber ser. La naturaleza labora hacia algo, tiene fines, y ello constituiría un bien absoluto, una fundamental autoafirmación del ser, un sí en contra de la nada. "Que al ser hay algo que le importa -al menos él mismo- es lo primero que sobre él puede enseñarnos la presencia de fines en él":u. La ética se convierte en $\mathbf{H}$. Jonas en un capítulo de la ontología. Frente a la acusación de incurrir en una falacia naturalista, es decir, de partir del ser en

33. Una resolución brillante de esta paradoja es, a mi entender, la fundamentación praxeológica de la ética de Antonio González. Véase "Fundamentos filosóficos de una civilización de la pobreza", ECA, mayo, 1997, p. 417 y ss. También su reciente libro Filosofía primera, op. cit., y mi comentario al respecto en "¿Existe una verdadera universalidad?". ECA, junio, 1997, p. 575 y ss.

34. Jonas, H., op. cit., p. 145. 
general para fundamentar un deber, y de pensar que la naturaleza confiere autoridad, $H$. Jonas afirmará que los que hablan de falacia naturalista mantienen otra metafísica, una metafísica dualista mediante la cual pueden disentir legítimamente de la naturaleza al invocar una instancia externa a ella ${ }^{15}$.

\section{F. Hinkelammert o la utilidad de lo inútil}

En cierto sentido, la ética de la responsabilidad de F. Hinkelammert puede ser entendida como un intento de llevar a cabo el proyecto original de $\mathrm{H}$. Jonas sin adiposidades metafísicas y alejándose de sus posiciones conservadoras. No se trata de una ética subordinada a la racionalidad instrumental como en Weber, ni de una ética ideal implícita ya en nuestra práctica cotidiana como en Apel, o de una ética subordinada a una determinada teoría metafísica como en Jonas. La ética de la responsabilidad de F. Hinkelammerl no surge de ninguna derivación a partir de una naturaleza humana. No cae en ningún momento en las redes de la falacia naturalista (derivar el deber del ser) ni aún en una reformulación sutil de la misma, como podría ser el caso en Apel. La ética de la responsabilidad de F. Hinkelammert surge de la voluntad de asegurar las condiciones de posibilidad de la vida humana. Esta voluntad exige hoy como presupuesto básico: el reconocimiento del otro como sujeto más allá de cualquier cálculo de utilidad. Es necesaria una constante relativización del cálculo de utilidad para asegurar la condición de posibilidad de la vida humana. El cálculo a largo plazo desemboca necesariamente en un cálculo del límite de lo aguantable. Pcro como el límite sólo se puede saher después de haberlo pasado, produce el problema que quiere evitar. Por eso esta ética de la responsabilidad, al introducir valores inútiles, surge en una relación de conflicto con el sistema. Los valores fundamentales del respeto al ser humano, a su vida en todas sus dimensiones y del respeto a la vida de la naturaleza no se justifican por ventajas calculables en términos de la utilidad o del intcrés propio, sino por ser la base de la vida huma- na sin la cual ésta se destruye en el sentido más elemental de la palabra. En este sentido, es útil oponerse al cálculo de utilidad: útil no torturar en ningún caso, por más razones de estado que se hallen; útil mantener las relaciones sociales vivas, aunque haya menos ganancias: útil conservar la naturaleza aunque disminuyan las tasas de crecimiento. No obstante, este reconocimiento de los valores humanos sigue siendo paradójico. Ellos tienen que ser reconocidos como valores, sin calcular su utilidad para que tengan el efecto de sostener un mundo en el cual es igualmente importante para la supervivencia que las decisiones se basen en un cálculo de utilidad. Se trata de que la razón instrumental se subordine a una ética de la responsabilidad y no a la inversa ${ }^{36}$.

Los antecedentes más cercanos de su ética los cifra Hinkelammert en K. Marx, que fue el primero en avizorar que la sociedad actual no es sostenible: "Por tanto, en la producción capitalista sólo sabe desarrollar la técnica y la combinación del proceso social de producción socavando al mismo tiempo las dos fuentes originales de toda riqueza: la tierra y el hombre ".3. Hinkelammert considera que las iesis centrales del análisis económico marxista no sólo no se han falseado sino que se confirman día a día: "Ciertamente no sólo el capitalismo produce este proceso de destrucción, sino que también el socialismo orientado por los criterios de maximización cuantitativa del producto ha generado efectos destructores análogos. Pero ello es una ampliación de la crítica de Marx, no su refutación" 3k. La insuficiencia de Marx no está para Hinkelammert en su análisis sino en la asunción de este perverso esquema del pensamiento moderno que proyecta en el futuro esquemas ideales larvados en el presente. El problema de Marx es que no puede ver la lucha de clases sino como un conflicto que apunta a la derrota definitiva de toda dominación como su polo contrario. Desaparece la conciencia de la contingencia del mundo y de la ambigüedad de la condición humana. De esta forma, el punto de partida de la ética de la responsabilidad se vira y desemboca en una ética irrespon-

35. Jonas, H., op. cil., p. 139.

36. Hinkelammert, F., Culuma de la esperanza y sociedad sin exclusión, op. cit., p. 223-224.

37. Marx. K.. El Capital. Tomo I. México: FCE. 1966. p. 423 y ss. Citado por Hinkelammert, F., Cultura de la Esperan:a, p 267.

38. Hinkelammert, F.. Cultura de la Esperanza y sociedad sin exclusión, op. cit., p. 268. 
sable capaz de sacrificar el presente por un futuro ilusorio ${ }^{39}$.

\section{La crítica del presente, la construcción del fu- turo y la ética}

Ahora bien, quizás por este mismo padrinazgo reconocido de Marx, en varios textos de Hinkelammert se percibe una cierta confusión o indiscernimiento entre ciencia crítica y ética filosófica. No deja de ser chocante la afirmación de F. Hinkelammert en el sentido de que "Los enunciados referentes a esta ética de la responsabilidad deberian ser considerados, por tanto, parte de las cien-

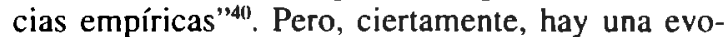
lución entre La cultura de la esperanza y sociedad sin exclusión, y su último artículo: "Asesinato es suicidio: de la utilidad de la limitación del cálculo de utilidad" donde se distingue claramente entre ciencia y ética. La distinción introducida por Max Weber entre investigación empírica o descripción, creo que sigue siendo sostenible. Los datos empíricos no pueden proporcionar ninguna base para establecer juicios de valor. Eso no quiere decir que no puedan formularse tales juicios e inclusive que no se pueda apelar a datos empíricos a tal efecto. Lo que no puede hacerse es considerar tales datos como prueba definitiva o como premisa de la cual se deriven los juicios. Sin embargo, esta distinción entre juicios de hecho y juicios de valor no autoriza a Max Weber a relegar a las ciencias sociales críticas al orbe de los valores. Puede concederse, incluso, que muchas veces estas ciencias críticas son puras edulcoraciones de bravatas morales, pero eso no obsta para que, de hecho, sea posible una ciencia crítica científica amoral. Es lo que con toda razón reclama Hinkelammert a Max Weber. La teoría económica y la metodología de las ciencias dominante, en la actualidad, impiden una toma de conciencia sobre la relación directa entre racionalidad instrumental y destrucción del ser humano y de la naturaleza, mediante la argucia de relegar toda ciencia social crítica que pone en evidencia esta relación al orbe de la moral.

En este sentido es perfectamente legítimo el reclamo de F. Hinkelammert de que es posible y deseable una ciencia empírica que se preocupe por las condiciones de posibilidad de la vida humana $y$, por consiguiente, de la racionalidad reproductiva. Esta ciencia, tal como ya la esbozó Marx, confrontaría de modo crítico la racionalidad medio-fin con su fundamento, que es el conjunto de las condiciones de posibilidad de la vida humana. En términos metodológicos, la condición de posibilidad de esta ciencia empírica es la existencia de juicios de hecho que no sean juicios medio-fin. Se trata de los juicios de hecho, cuyo criterio de verdad es el criterio de vida o muerte y no el de falsación/ verificación. O dicho de otro modo, de juicios de hecho del tipo "si continuamos haciendo esto o lo otro desaparecemos como humanidad" que no pueden ser jamás verificados, pues su cumplimiento entraña la muerte de todo verificador posible. Su objeto es asimismo analizar las acciones medio-fin bajo el punto de vista de su compatibilidad con la racionalidad reproductiva, y dar criterios para moderar la racionalidad instrumental siempre y cuando resulte incompatible con la racionalidad reproductiva. Pero no se trata de una ciencia ética sino simplemente de una ciencia crítica que intenta dar cuenta del fundamento de los hechos. Como ciencia, no puede decir si la humanidad debe sobrevivir, pero sí puede hacer un juicio sobre si puede sobrevivir bajo determinadas circunstancias o no. Estos juicios no pueden relegarse, como pretende Weber, a la esfera de la ética.

Pero tampoco basta con la reivindicación de una ciencia empírica crítica que analice los hechos desde la perspectiva de la vida y la muerte de los actores. Como insistirá Antonio González ${ }^{4}$, para que esta crítica científica sea efectiva se necesita mostrar no solamente cuál es el fundamento últi-

39. Ibid, p. 268 y ss.

40. Ibid., p. 224.

41. González, A., "Hacia una fundamentación de las ciencias sociales", en Para una filosofía liberadora, UCA editores, 1995; Las ciencias sociales no pueden ser mera observación positiva sin interpretación ni crítica, ni mera hermenéutica sin constatación de hechos ni crítica, ni mera teoría crítica sin constatación de hechos e interpretación. El positivismo y la descripción rigurosa de los hechos no son incompatibles con el ejercicio crítico de las ciencias sociales. Si la razón es búsqueda permanente para dar cuenta de los hechos, el uso de la razón que hacen las ciencias sociales no tiene porqué ser moral o ético. La crítica social científica consiste justamente en mostrar el fundamento de unos determinados hechos sociales y deja de ser crítica cientifica cuando contrapone a los hechos unos valores ideales. 
mo de la realidad social y apelar a unos valores éticos distintos de los vigentes, sino mostrar también que ese fundamento real podría ser otro. Mostrar, en definitiva, que hay alternativas viables y razonables. Ante las bravatas morales, los defensores del sistema siempre pueden responder lacónicamente: "muy bien, tienes toda la razón pero, ¿cuál es tu alternativa?". El problema se agrava si consideramos que hoy el capitalismo utópico ha dado paso a un capitalismo cínico ${ }^{42}$, que es inmune a la crítica científica porque no tiene necesidad de esconder su propio fundamento, ni de negar lo que realmente está pasando. Es un capitalismo que admite sin tapujos que para los pobres es un privilegio ser explotado, que se está construyendo un gran muro entre países ricos y pobres y que la muerte espera a los más. El capitalismo, probablemente por su victoria total, cada vez tiene menos necesidad de eufemismos y de rostros humanos y asume perfectamente sin rubor toda crítica social ${ }^{43}$. Entonces, ¿cómo criticar hoy al capitalismo si la crítica científica, aún bien combinada con la diatriba moral, deja de ser operante?

Para que la crítica de las ciencias sociales sea operante se requiere, además de la crítica y de la apelación a unos determinados valores, de la elaboración de alternativas viables ${ }^{44}$. Toda ciencia crítica que pretenda ser verdaderamente crítica no debe quedarse en la crítica del presente, si no que debe esforzarse para pensar alternativas razonables. En todas las áreas siempre estamos más facultados para la crítica que para la reconstrucción. Particularmente en filosofía es mucho más fácil criticar unas determinadas tesis que atreverse a mantener otras. Además, el que propone alternativas se expone a la crítica mientras que el crítico que es sólo crílico se inmuniza contra ella. El mismo planteamiento de un orden alternativo viable y de estrategias que vayan realizándolo puede ser un magnífico detonante para aglutinar fuerzas capaces de empujarlo. Sobre lodo cuando no se trata de una aproximación asintótica sino de un orden nuevo que encuentra espacios para establecerse en el interior del mismo sistema capitalista ${ }^{45}$. Ahora bien, cuando se introducen alternativas, por más viables que sean, se introducen necesariamente valores porque se está presuponiendo un orden de cosas que se considera preferible al actual. Mientras la crítica de las ciencias sociales no es necesariamente ética, pues no se necesita para la crítica apelar a ningún criterio exterior a la ciencia misma, la elaboración de alternativas en cualquier sentido implica siempre una opción moral, la apelación a una ética extrínseca a la ciencia. Marx probablemente tenía razón al criticar el pensamiento utópico aislado de todo análisis del presente y de sus posibilidades históricas, pero se equivocaba al negar la autonomía y la necesidad de una opción ética y mantener una concepción teleológica y providencialista de la historia.

La ciencia social crítica que propone Hinkelammert puede prever un suicidio colectivo, pero de esta previsión no se sigue que es preferible cambiar el sistema y seguir viviendo. Las ciencias pueden informarnos de que determinadas acciones nos causarán la propia muerte, pero, incluso en este caso extremo, hay personas que pueden optar por el suicidio o pueden preferir las ventajas temporales que proporcionan unas determinadas acciones, aunque sepan que, a la larga, ella les acarreará la muerte o que sus hijos no podrán vivir como ellos. La ciencia nos informa sobre los nexos de causas y consecuencias a los que está sometida, al menos parcialmente, la acción humana. Pero la decisión de poner en marcha ciertos efectos de nuestras acciones y no otros, deshorda

42. Hinkelammert. F. "El capitalismo cínico y su crítica: la crítica de la ideología y la crítica del nihilismo”, inédito, septiembre, 1997.

43. Es interesante la comparación que establece Hinkelammert de este capitalismo cínico con el nazismo. Esta manera de decir y hacer lo que se hace y se tiene planificado fue lo que hizo Hitler en el parlamento alemán. Los políticos liberales acostumbrados a decir una cosa y a hacer otra no le creían y buscaban detrás de lo que decía sus verdaderas intenciones. Del mismo modo que con Hitler desapareció la hipocresía, desaparece ahora en el capitalismo y por eso es mucho más duro de combatir porque ya no basta con mostrar sus falacias o artimañas. Hinkelammert, F., "El capitalismo cínico y su crítica: la crítica de la jdeología y la crítica del nihilismo", inédito, septiembre, 1997.

44. Es lo que esboza entre otros David Schweickart, Against Capitalism, Westview Press, Colorado, 1976.

45. Ibid., véase también González, A., “QQué queda del socialismo?”, Realidad, No. 55, enero-febrero, 1997. 
el campo de la pura ciencia y nos sumerge en el ámbito de la ética. En general, hoy las ciencias sociales renuncian a la pretensión de predecir mecánicamente el porvenir de la historia humana aunque pueden avanzar hipótesis, escenarios y tendencias más o menos certeras. Parece evidente que la acción humana no se puede predecir científicamente en todos sus detalles y que, por tanto, el futuro de la humanidad cae también dentro del ámbito de la responsabilidad humana, tanto individual como colectiva, y exige una reflexión estrictamente ética. La recuperación del carácter contingente de la historia, de la autonomía de la ética y la liquidación del esquema utópico moderno permiten justamente un realismo utópico en el que las posibilidades que descubrimos en el presente pueden ayudar activamente a cambiarlo. El reconocimiento de una dimensión ética en toda ciencia social, sin mengua de una distinción clara entre ciencia y ética, nos permite precisamente criticar a Weber más que por intentar diferenciar los juicios de la élica, de los de la ciencia, por asumir implícita y vergonzantemente los valores que presupone la alternativa social vigente al pretender que la ciencia no contiene ninguna dimensión valorativa.

Pero del mismo modo que decimos que no hay alternativas sin una ética, hay que decir que tampoco hay alternativa al renunciar a la teoría científica y a su intento de asepsia valorativa. La ciencia cuando pretende eliminar la ética no hace más que mistificar las cosas. La ética que desprecia las ciencias incurre en una posición ingenua, pues si bien es evidente que los grandes problemas de la humanidad son creados por esta civilización cienlífico-técnica, vivimos en un grado de complejidad tal, que sin la ayuda de la ciencia y de la lécnica tampoco podrían solucionarse. La ciencia tiene capacidad para acabar con la vida sobre la tierra. Pero cinco mil millones de seres humanos nunca podrán sobrevivir sobre este planeta si no es recurriendo a las ciencias. Pretender un regreso a formas de vida tradicionales es otra forma de suicidio. Reiteradamente la crítica ética, aislada del recurso a las ciencias, incurre en el error que Marx atribuía a los socialistas utópicos, el de pensar que hastá esta crítica para forjar el futuro. Una ciencia crítica que pretenda ser operativa tiene que contemplar estos tres momentos en radical unidad: la crítica del presente, las alternativas posibles y los valores desde las que se formulan. La falta, preponderancia o negación de la autonomía de alguno de estos tres momentos no hace más que lisiar las posibilidades de cambio.

\section{El suicida y la fundamentación ética}

La necesidad de unos valores que orienten las mismas ciencias y de unas ciencias sociales que reconozcan una inexorable dimensión ética en sus elaboraciones lleva a Hinkelammert a plantear una ética de la responsabilidad, cuyo principal opositor no es ya el escéptico como en Apel ni el cínico como en Dussel ${ }^{46}$, sino el suicida. ¿Sería legítimo y moral el suicidio colectivo de la humanidad si éste fuera fruto de una voluntad general libre de toda coacción'? Hinkelammert resalta el hecho de que muchos seres humanos que se colocan voluntariamente en el límite de la vida (conducir a velocidades cada vez mayores, abrir el paracaídas cada vez a menos metros del suelo, etc.) mueren risueños. La muerte tiene algo de fascinante y atractiva. Parecería que para todo Nibelungo la muerte es un valor superior a la vida y que del análisis ético lo máximo que puede desprenderse es que la decisión por la vida tiene el mismo valor que la decisión por la muerte. En último término, entonces, ¿tan racional es optar por la muerte como optar por la vida? Creo que Hinkelammert nos diría que sí. El suicidio no es un crimen, o al menos no admite parangón con el asesinato. "El crimen se comete en relación con valores $y$, en consecuencia, le corresponde un castigo. El suicidio, en cambio, disuclve los valores y, por ello, no hay castigo posible. $\mathrm{Ni}$ es posible considerarlo un crimen, por más que la negación al suicidio sea la raíz de toda realidad y de todos los valores"47. Para las éticas liberales que en general resaltarán el principio de autonomía como principio fundante respecto al principio de justicia y de beneficencia, el suicidio no es más que hacer uso de la propia libertad sobre el propio cuerpo. Apel calla cuando piensa en la posibilidad de un consenso de la comunidad ideal de comunicación sobre el suicidio.

46. Véase el paso del escéptico al cínico en Apel, K. O., "La ética del discurso ante el desalío de la filosofía latinoamericana de la liberación", Isegoría. 1995, pp. 108-125.

47. Hinkelammert. F., Cultura de la esperanza y sociedad sin exclusión, op. cit., p. 281. Del mismo modo se expresa Wittgenstein. Véase cita de Hinkelamment, F., ibíd., p. 281. 
Para una razón comunicativa tampoco parece que sea irracional el suicidio si éste es fruto de un consenso pleno y sin coacción. Para diversos filósofos existencialistas, la muerte libre es el único vencimiento de la muerte. Esta actitud ya está prefigurada en los viejos estoicos: "En nada debemos satisfacer tanto a nuestro espíritu como en la elección de la muerte; que salga por donde quiera, por el hierro, por la cuerda o por el veneno; ;apresúrese y rompa los lazos de su esclavitud! Si debemos satisfacer a los demás en la manera de vivir, a nadie debemos satisfacer más que a nosotros mismos en la manera de morir. La muerte que nos agrada es la mejor"4x. Todos, incluso los esclavos son libres para morir. "¿Te agrada vivir? Vive. ¿No te agrada vivir? Puedes volver al punto donde saliste. Muchas veces te has hecho extraer sangre para aliviarte un dolor de cabeza: para debilitar el cuerpo se abre la vena; no es necesario hacerse ancha herida en el pecho; un punzón basta para abrir el camino de esa gran libertad, y ese descanso sólo cuesta un momento"4". Para Jonas cabe hablar del derecho individual al suicidio, pero no del derecho de la humanidad al suicidio. Jonas fundamenta desde su metafísica un deber incondicional de la humanidad para la existencia y para la humanidad futura de la que nunca se puede presuponer su conformidad con el suicidio ${ }^{50}$.

Hinkelammert no considera factible u honrada filosóficamente esta salida de $\mathbf{H}$. Jonas, pero el matíz importante que introduce Hinkelammert respecto al pragmatismo y las éticas liberales, es que las técnicas o medios para suicidarse y toda la literatura existente al respecto utilizan juicios de hecho que no son de racionalidad medio-fin. Primero porque la vida y la muerte no son un fin entre otro cualquiera (hacer zapatos, nadar, etc.) sino la posibilidad o imposibilidad de tener fines y, segundo, porque el éxito de toda técnica de suicidio es inverificable. El suicida no puede comunicarnos el éxito de su técnica. El suicidio, a diferencia de los otros fines, no se puede repetir ni comprobar intersubjetivamente ${ }^{51}$. En definitiva, el que la vida y la muerte de la humanidad no sea expresable en juicios de racionalidad instrumental medio-fin, no significa que no haya posibilidad de pronunciar juicios de hecho y, por tanto, de elaborar una ciencia empírica al respecto. No obstante, hay que enfatizar que para Hinkelammert, la ética de la responsabilidad y su axiología: respetar a los demás, a la naturaleza y a uno mismo, no se fundamenta en esta ciencia empírica sobre la vida y la muerte de la humanidad, sino en la libertad humana y en su opción por la vida: "Se trata de la esperanza de que, en última instancia, la humanidad se va a negar a esta mística de la muerte. Sin esta esperanza, la crítica del sistema nihilista es imposible. Pero no se puede basar en ninguna seguridad. También la humanidad se puede decidir a favor de la nueva marcha de los Nibelungos, que llegaron a la corte del rey Atila para morir. Aparece una opción, que es la única opción básica de la vida humana: se trata de la opción por la vida, que se niega a la opción, muchas veces atractiva, por la muerte"s? En Hinkelammert no hay propiamente una fundamentación de la ética, pues no hay ninguna instancia que pueda justificar alguna obligación moral más alla de la decisión por la vida o por la muerte.

El problema, a mi entender decisivo, es la concepción de la razón. Si la entendemos al modo de Hume no se puede decir nada más que lo que dice Hinkelammert, pero si la entendemos al modo zubiriano, la marcha de los Nibelungos es cuanto menos una renuncia al dinamismo de la razón sentiente. No se trata de elegir entre una concepción u otra, sino de ver cuál se atiene más escrupulosamente a los hechos y cuál es un prejuicio. Para Hume "no contradice a la razón el que yo prefiera la destrucción del mundo entero que un rasguño en mi dedo"'5?. El problema es que Hume introduce una división entre sentir e inteligir que no está justificada sin más. Para Hume, la razón sólo se ocupa del conocimiento de lo verdadero y de lo falso, entendiendo por tal la correspondencia entre nuestras afirmaciones y la experiencia. De ese modo, los sentimientos y deseos jamás pueden

48 Séneca, Epistolas morales, Edaf, Madrid, 1971, p. 1241. Citado por Hinkelammert, ibíd., p. 279.

49. Ibid., p. 1616, citado por Hinkelammert, ibid, p. 279.

50. Jonas, H., "La humanidad no tiene derecho al suicidio", op. cit., p. 79.

51. Hinkelammert, F., Cultura de la esperanza y sociedad sin exclusión, op. cit., p. 279.

52. Hinkelammert, F., "Asesinato es suicidio: de la utilidad de la limilación del cálculo de utilidad", inédito, septiembre, 1997.

53. Hume, D., Treatise II, 3, 3. 
contradecir a la razón. La razón está subordinada a la voluntad y no hace más que secundarla en sus apetencias. Toda afirmación moral no es, en último término, más que la expresión de nuestros deseos o sentimientos. Así, si ante la presencia de un asesinato los humanos tendemos a emitir un juicio desaprobatorio, a condenar la acción como mala, es porque la consideración del acto produce en nosotros un sentimiento de desagrado tal, que lo rechazamos de modo instintivo. Pero de aquí se colige inmediatamente que si el acto produjera en nosotros una sensación de agrado, entonces el asesinato sería bueno. Si yo quiero suicidarme es bueno suicidarme. La razón en lugar de ser el árbitro es ahora la criada del sentir.

En Zubiri se suprime radicalmente este dualismo ancestral entre sentir e inteligir que corroe toda la historia de la filosofía occidental ${ }^{54}$. La razón no es el árbitro ni la criada sino que está pergueñando siempre toda actividad humana. La razón sentiente zubiriana es una razón creadora lanzada a profundizar en las cosas y a revocar y revisar todo género de categorías ${ }^{55}$. Los actos racionales tienen, por su propia índole, un impulso de alteridad de carácter universalizador o crítico, que me llevan en el terreno de la actividad científica a cuestionar si realmente el fundamento de las cosas es el que se dice y en el terreno moral a plantearme si mis bienes y virtudes no atentan contra los bienes y virtudes de los demás ${ }^{56}$. Desde esta perspectiva podrá ser racional, en algunos casos, el suicidio individual, pero no siempre y nunca el suicidio colectivo de la humanidad, pues para este suicidio colectivo se tendría que renunciar a este ímpetu de alteridad que me lleva a preguntarme por los intereses de los otros, incluso de los no nacidos. La obligación primordial inscrita en nuestros actos no es más que este impulso de alteridad del dinamismo de la razón ${ }^{37}$. La exigencia de responsabilidad desde una filosofía primera que intenta una descripción trascendental de los actos humanos, no surge de una opción por la vida sino que es anterior a toda opción por la vida o por la muerte. Pero a diferencia de H. Jonas, aquí no se recurre a ninguna metafísica sino a una filosofía primera entendida como ciencia positiva radical ${ }^{38}$. $\mathrm{Se}$ coincide con $\mathrm{H}$. Jonas en considerar que el consenso no es la última palabra sobre el bien y la justicia, pero no se confía en la virtud ni en la racionalidad de los sabios. Los actos racionales son propios de todo ser humano y, en consecuencia, a unas instituciones que fueran verdaderamente democráticas y que no se sustentaran de hecho en instituciones y formas de vida no universalizables, sólo cabría medializarlas por la fuerza de la razón, no por instituciones autoritarias. Lo decisivo es que esta fuerza de la razón es un hecho aprehendible para cualquiera y accesible mediante el análisis filosófico, no una ficción útil ni una experiencia levinasiana del Rostro del Otro que podríamos tener o no tener. Una filosofía primera no puede decir por qué se da este hecho y por qué existe este momento racional en los seres humanos. Se limita a constatarlo. No se trata tampoco aquí de una aproximación asintótica a una racionalidad total. La exacerbación de la razón, aún de una razón sentiente, la continua presencia de nosotros ante nosotros mismos, el análisis infinito de

54. Zubiri, X., Inteligencia sentiente, Madrid: Alianza editorial, 1980.

55. Zubiri, X.. Inteligencia y razón, Madrid: Alianza editorial, 1983.

56. Véase A. González y su fundamentación praxeológica de la ética a partir de una filosofía primera de la acción en Filosofia primera. op. cit.

57. Una objeción inmediata que podría hacerse a la fundamentación praxeológica de la ética es que se trata de una reactualización de Kant, pero la diferencia decisiva es que el análisis trascendental kantiano persigue una descomposición de las facultades para detectar sus formas y conceptos a priori, mientras que el análisis trascendental de Zubiri y de A. González es un análisis de los actos mismos en su inmedialez. En Kant, el "factum moral" aparece como una simple conciencia inmediata del deber, como un imperativo que ya debemos suponer al comienzo mismo del análisis. En el análisis de Antonio González surge de la constatación del hecho o dinamismo de un tipo de actos humanos, los actos racionales. El punto de partida kantiano es discutible, pero la descripción de A. González pretende tener la positividad y rotundidad de los hechos.

58. La diferencia y a la vez el parecido entre el método de la fenomenología y el método zubiriano está muy bien expuesto en el capitulo "Análisis de hechos y descripción de fenómenos" de la tesis de González, A., Un solo Mundo, la relevancia de Zubiri para la teoría social, Madrid, Comillas, 1995. 
nuestros actos nos paraliza y nos lleva a un universo patológico e invivible. En el límite la razón mata tanto como la sinrazón. Se trata, más bien, de constatar como un hecho que siempre hay una cierta tensión u oposición insoluble, no regida por el principio de superación y no clausurable, entre actos racionales y actuaciones cotidianas, entre razón y logos.

¿Pero qué cambia, podemos seguir preguntándonos, si por más que haya una fuerza de la razón, un impulso de alteridad que me lleva a respetar a los demás, al planeta entero y aún a los no-nacidos, yo siempre puedo elegir actuar irracionalmente? Sin duda, la libertad humana continua siendo decisiva. Tenemos que reconocer que al suicida cualquier argumentación filosófica probablemente lo dejará más frío que la profecía del clarividente a los Nibelungos. Es lo que retrata la experiencia de Dennis Meadow, coordinador del informe del Club de Roma sobre los límites del crecimiento: "Suliciente tiempo he tratado de ser un evangelista global, $y$ he tenido que aprender que no puedo cambiar el mundo. Además, la humanidad se comporta como un suicida, y no tiene sentido argumentar con un suicida una vez que ha saltado de la ventana"sy. Claro está que la humanidad que se comporta como un suicida es apenas una cuarta parte de la humanidad, una cuarta parte de la huinanidad que pone en el borde de la muerte a la mayoría de la humanidad, pero aún concediendo que éste no fuera el caso, hay que reconocer que una fundamentación ética, como cualquier otra fundaınentación filosófica, sólo puede convencer al que tenga un interés filosófico, esto es un interés por la verdad ${ }^{(x)}$. Una fundamentación filosófica de la ética no puede consistir en utilizar la razón de la fuerza, de la emotividad o de la persuasión, sino simplemente en la mostración filosófica del hecho de una obligación primordial. Este hecho afecta indistintamente al escéptico, al cínico y al suicida y es previo e independiente de toda opción humana. Hinkelammert, al no apreciar este hecho o considerar imposible una fundamentación no falaz de la ética, creo que se instala, contra su propio deseo, en una posición humana. A la voluntad de muerte y sus valores sólo se le puede oponer una voluntad de vida, como si los actos racionales de los individuos fueran un mero brazo ejecutivo de los sentimientos y deseos humanos. Es importante, para evitar el terror y el totalitarismo, bajar del tribunal de la modernidad a la razón, pero si en su lugar se erige el tribunal de la voluntad, entonces, quizás estemos más perdidos. Con todas sus diferencias, la ética de la responsabilidad de F. Hinkelammert se enfrenta a una problemática parecida a la ética de la liberación de E. Dussel. Ambas renuncian a cualquier fundamentación ética por la vía de una melafísica de la historia, y ambas encuentran insuficientes e ideológicos otros intentos contemporáneos de fundamentación de la ética, como los de Apel o de H. Jonas, pero en lugar de intentar una fundamentación más firme de la ética, apelan a una experiencia del Otro o a una opción por la vida que no es universal ni obliga a todos. ¿Esta desfundamentación de la ética no será más fruto de un prejuicio contemporáneo que del atenimiento escrupuloso a los hechos? Es, quizás, la interrogante que tiene que replantearse una filosofía de la liberación con toda radicalidad.

\section{Jordi Corominas}

59. Der Spiegel, No. 29. 1989, p. 118 . Citado por Hinkelammert en Cultura de la esperanza y sociedad sin exclusión. op. cit.. p. 168.

60. Esta es la respuesta que da Apel a la objeción que le pone Dussel de que la ética del discurso no sirve para el cínico. Véase Apel. op. cit. La respuesta es válida también para el suicida siempre y cuando la fundamentación no sea ya discursiva sino praxeológica, pues ya hemos visto que un consenso ideal tiene que aceptar la posibilidad de un suicidio colectivo. 